\title{
Resistência de plântulas de pepineiro a Colletotrichum lagenarium induzida por frações de extrato de Saccharomyces cerevisiae
}

\author{
Nívea Maria Tonucci Zanardo(1), Sérgio Florentino Pascholati ${ }^{(1)}$ e Maurício Batista Fialho(1) \\ (1)Universidade de São Paulo, Escola Superior de Agricultura Luiz de Queiroz, Setor de Fitopatologia, Caixa Postal 09, CEP 13418-900 Piracicaba, SP. \\ E-mail: nmtzanardo@hotmail.com, sfpascho@esalq.usp.br, fialhomb@hotmail.com
}

Resumo - O objetivo deste trabalho foi purificar frações do extrato de Saccharomyces cerevisiae que induzam a resistência do pepineiro a Colletorichum lagenarium e determinar sua eficiência na proteção de plântulas, em casa de vegetação. A suspensão de células da levedura, seus extratos brutos aquosos autoclavados por 4 e 10 horas, duas frações (sobrenadante e precipitado) resultantes da precipitação etanólica do extrato bruto (4 horas) e as frações do sobrenadante identificadas na cromatografia de troca aniônica foram aplicados a cotilédones de plântulas de pepino. A suspensão de células de levedura não apresentou controle significativo da doença. Os extratos brutos autoclavados reduziram a severidade da antracnose entre 82 a $86 \%$ e as frações resultantes da precipitação etanólica em $98 \%$. As frações do sobrenadante não ligadas à resina DEAE-celulose (pico I da cromatografia) ou ligadas à resina (pico II) - constituídas principalmente por carboidratos - foram as mais efetivas na indução de resistência nas plântulas e reduziram a severidade da antracnose em 81 e $72 \%$, respectivamente. A autoclavagem de extratos brutos aquosos de $S$. cerevisiae é necessária para a extração de moléculas eliciadoras da resistência a C. lagenarium, em cotilédones de pepineiro.

Termos para indexação: carboidratos, eliciadores, extrato de levedura, indução de resistência, patógeno.

\section{Resistance of cucumber seedlings to Colletotrichum lagenarium induced by fractions of Saccharomyces cerevisiae extract}

\begin{abstract}
The objective of this work was to purify the Saccharomyces Cerevisiae extract fractions that induce resistance to Colletorichum lagenarium in cucumber and to determine their efficiency in protecting seedlings in the greenhouse. Yeast cell suspension, its crude aqueous extract autoclaved for 4 and 10 hours, two fractions (supernatant and pellet) resulting from ethanolic precipitation of the crude extract (4 hours) and the supernatant fractions identified in anion exchange chromatography were sprayed onto cucumber cotyledons. The yeast cell suspension did not significantly control the disease. The autoclaved crude extracts reduced the anthracnose severity between 82 and $86 \%$, and the ethanolic precipitation fractions in $98 \%$. The supernatant fractions non-adsorbed (chromatography peak I) and adsorbed (peak II) to DEAE-cellulose resin, containing mainly carbohydrates, were the most effective for inducing assistance to the seedlings, and reduced the anthracnose severity in 81 and $72 \%$ respectively. Autoclaving crude extracts of $S$. cerevisiae is necessary to extract molecules that elicit resistance to C. lagenarium in cucumber cotyledon.
\end{abstract}

Index terms: carbohydrates, elicitors, yeast extract, resistance-induction, pathogen.

\section{Introdução}

O fungo Colletotrichum lagenarium, agente causal da antracnose das cucurbitáceas, apresenta como sinonímias C. orbiculare e C. gloeosporioides f. sp. cucurbitae. A doença é importante pela frequência em que ocorre e pelos danos que causa na cultura do pepino e em outras cucurbitáceas, como chuchu, melancia, melão e abóbora (Kurozawa \& Pavan, 1997). A disseminação do patógeno se dá principalmente por respingos de chuva, insetos e equipamentos agrícolas. Entre as medidas de controle recomendadas estão a utilização de sementes sadias, o emprego de cultivares resistentes, a rotação de culturas, a eliminação dos restos de cultura e de cucurbitáceas silvestres, o manejo adequado da irrigação e o uso de fungicidas (Kurozawa et al., 2005).

Atualmente, a indução de resistência sistêmica de plantas cultivadas a doenças tem recebido destaque na pesquisa agrícola. $\mathrm{O}$ fenômeno de indução consiste no aumento da capacidade da planta em expressar respostas de defesa contra a infecção por patógenos, por meio do 
tratamento com agentes indutores (eliciadores), sem alterações no genoma da planta (Stadnik, 2000).

Os indutores bióticos podem ser organismos vivos, parte desses, ou mesmo seus metabólitos. Eles atuam como eliciadores capazes de ativar respostas de defesa localizada ou sistêmica em plantas (Di Piero et al., 2005). Os eliciadores comumente isolados e identificados pertencem a diferentes classes químicas, como carboidratos, peptídeos, proteínas, lipídeos, glicoproteínas, glicopeptídeos, ácidos graxos, entre outros (Walters et al., 2005).

Entre os eliciadores derivados de fungos, muitos estão presentes na levedura Saccharomyces cerevisiae. O extrato da levedura contém vários componentes que podem eliciar respostas de defesa, como quitina, oligômeros de $\mathrm{N}$-acetilglucosamina, beta-glucanas, glicopeptídeos e ergosterol (Boller, 1995). Diversos trabalhos mostraram o potencial de compostos eliciadores de células da levedura S. cerevisiae, na ativação de repostas de defesa contra fitopatógenos e no controle de doenças em plantas de milho, sorgo, eucalipto e maracujá (Pascholati, 1998).

O objetivo deste trabalho foi purificar frações de $S$. cerevisiae que induzam resistência do pepineiro a $C$. lagenarium e determinar sua eficiência na proteção de plântulas de pepino, em casa de vegetação.

\section{Material e Métodos}

Sementes de pepineiro, Cucumis sativus L. cv. Caipira Verde, foram semeadas em bandejas de isopor, com o substrato agrícola Plantmax (Eucatex Agro, Paulínia, SP). Sete dias após a semeadura, as plântulas foram retiradas das bandejas e transferidas para vasos com mistura de solo, areia e matéria orgânica autoclavados, e foram mantidas quatro plântulas por vaso. $\mathrm{O}$ experimento foi realizado no interior de casa de vegetação convencional, com temperatura média de $34^{\circ} \mathrm{C}$.

Para o isolamento do fungo Colletotrichum lagenarium, procedeu-se à coleta de folhas de pepino com sintomas de antracnose e à desinfestação, com hipoclorito de sódio comercial a $2 \%$, de fragmentos foliares obtidos a partir da área de transição entre o tecido sadio e o doente. Em seguida, os fragmentos foram colocados na superfície do meio de cultivo ágar-água (AA) a 2\%. Após a obtenção das culturas puras, o fungo foi transferido para placas com o meio de cultivo aveia-ágar, para estimular a esporulação. $\mathrm{O}$ material foi incubado em câmara de crescimento a $25^{\circ} \mathrm{C}$, sob luz UV de comprimento de onda longo (NUV).
Células da levedura de panificação $\left(200 \mathrm{~g} \mathrm{~L}^{-1}\right)$ foram ressuspensas em água destilada e centrifugadas a $15.000 \mathrm{~g}$ por $30 \mathrm{~min}$, entretanto, não foram submetidas à autoclavagem, para que se pudesse avaliar o efeito apenas da suspensão de células no controle da enfermidade. Como controle negativo, as plântulas foram pulverizadas com água destilada, e no controle positivo foram pulverizadas com o indutor de resistência Bion (Syngenta Proteção de Cultivos Ltda., São Paulo, SP), na concentração 0,005 g $100 \mathrm{~mL}^{-1}$.

Para a extração das moléculas eliciadoras de S. cerevisiae, foi utilizada levedura de panificação (fermento biológico Fleischmann, AB Brasil Indústria e Comércio de Alimentos Ltda., Jundiaí, SP), em tabletes de $200 \mathrm{~g}$ dissolvidos em $1 \mathrm{~L}$ de água destilada (Wulff \& Pascholati, 1999). Para melhorar a extração e solubilização das moléculas eliciadoras, a levedura foi submetida à autoclavagem a $121^{\circ} \mathrm{C}$, conforme Bonaldo (2005). A suspensão de células de $S$. cerevisiae foi autoclavada em quatro etapas, com intervalos de tempo diferentes. Na primeira etapa, o material foi autoclavado por 1 hora, na segunda, por 2 horas, na terceira, por 3 horas e, na quarta, por 4 horas. Em cada etapa de autoclavagem, foi realizado o resfriamento do material em banho de gelo e, após a autoclavagem, a preparação foi centrifugada a $15.000 \mathrm{~g}$, por $30 \mathrm{~min}$, a $4^{\circ} \mathrm{C}$. O precipitado celular foi descartado, e o sobrenadante considerado como extrato bruto aquoso autoclavado (10 horas). A extração de moléculas eliciadoras também foi realizada com outro protocolo de autoclavagem; a suspensão da levedura foi autoclavada a $121^{\circ} \mathrm{C}$ em quatro etapas de 1 hora cada uma, e o resfriamento do extrato foi realizado em banho de gelo em cada intervalo de autoclavagem; após a autoclavagem, a preparação foi centrifugada a $15.000 \mathrm{~g}$, por $30 \mathrm{~min}$, o precipitado celular foi descartado, e o sobrenadante obtido foi considerado como extrato bruto autoclavado (4 horas).

Para a obtenção do precipitado e do sobrenadante do extrato bruto de $S$. cerevisiae autoclavado $(4 \mathrm{~h})$, foi adicionado álcool etílico, lentamente, ao extrato sob agitação, mantido a $4^{\circ} \mathrm{C}$, na proporção de $1: 1(\mathrm{v} / \mathrm{v})$. Após três dias de repouso, o material foi centrifugado a $5.200 \mathrm{~g}$ por $45 \mathrm{~min}$, e o precipitado ressuspenso em água e armazenado em congelador. O álcool foi evaporado do sobrenadante por meio de aquecimento a $50^{\circ} \mathrm{C}$, sob pressão reduzida e, após a evaporação, o sobrenadante resultante $(750 \mathrm{~mL})$ foi dialisado 
(membrana com limite de exclusão 12.000-14.000 Da), contra $15 \mathrm{~L}$ de água destilada, a $4^{\circ} \mathrm{C}$, por 48 horas; foram realizadas cinco trocas de água (Labanca, 2002). Após a diálise, a amostra foi concentrada com polietilenoglicol 20.000 até o volume final de $25 \mathrm{~mL}$ e, em seguida, armazenada e congelada. Em cada etapa de purificação, foram determinadas as concentrações de proteínas e carboidratos totais.

Optou-se por somente identificar e fracionar, por meio da realização da CTA, os componentes do sobrenadante da precipitação etanólica, já que o precipitado mostrouse pouco solúvel em água, o que dificultaria seu uso em pulverizações. Para realização da cromatografia de troca aniônica (CTA), uma amostra de $4 \mathrm{~mL}$ do sobrenadante obtido da precipitação etanólica foi aplicada à coluna DEAE-celulose e equilibrada com tampão Tris- $\mathrm{HCl}$ $0,01 \mathrm{~mol} \mathrm{~L}^{-1}(\mathrm{pH}$ 8). $\mathrm{O}$ material adsorvido à resina foi eluído, tendo-se utilizado as concentrações de 0,115 , 0,215, 0,500 $\mathrm{mol} \mathrm{L}^{-1}$ e fluxo de $4 \mathrm{~mL} \mathrm{~min}^{-1}$ e coletado as frações de $5 \mathrm{~mL}$. As frações foram reunidas de acordo com os picos de absorbância a $280 \mathrm{~nm}$, dialisadas contra água destilada. $\mathrm{O}$ volume inicial de cada pico (frações agrupadas) foi concentrado três vezes, tendo-se utilizado polietileno glicol (PEG 20.000), e utilizado nos bioensaios com cotilédones de pepineiro. $\mathrm{O}$ material submetido à coluna de CTA foi filtrado (filtro com poros de $0,2 \mu \mathrm{m}$ de diâmetro) e desgaseificado por $10 \mathrm{~min}$.

Durante a realização do bioensaio, cotilédones de plântulas de pepineiro foram pulverizados com os seguintes tratamentos: suspensão de células da levedura não autoclavada, extratos brutos autoclavados (4 ou 10 horas), frações obtidas por precipitação etanólica (sobrenadante e precipitado) ou por CTA, e os controles (água destilada e Bion). Após três dias do tratamento eliciador, uma suspensão de conídios de C. lagenarium (105 conídios $\mathrm{mL}^{-1}$ ) foi pulverizada nas plântulas, que foram mantidas em câmara úmida por 24 horas. Os bioensaios foram realizados em câmara de crescimento (tipo BOD) a $26^{\circ} \mathrm{C}$, com fotoperíodo de 12 horas luz/escuro. A severidade da doença foi avaliada após quatro ou cinco dias da inoculação do patógeno, de acordo com o aparecimento das lesões nos cotilédones tratados com água destilada. Para tal, cada cotilédone foi destacado da plântula e escaneado para quantificação da área lesionada, com auxílio do programa Quant (Vale et al., 2003). O delineamento utilizado foi o inteiramente ao acaso, com quatro repetições e quatro plântulas por vaso.
A dosagem de proteínas das amostras foi realizada conforme Bradford (1976), tendo-se utilizado como padrão albumina de soro bovino. Os carboidratos totais foram quantificados, nas amostras, pelo método fenol sulfúrico (Dubois et al., 1956), tendo-se utilizado glicose como padrão.

\section{Resultados e Discussão}

Os cotilédones tratados com os extratos brutos autoclavados por 4 ou 10 horas apresentaram redução significativa ( 86 e $82,2 \%$, respectivamente) na severidade da doença, quando comparados aos cotilédones tratados com água (Figura 1). A suspensão de células de $S$. cerevisiae não autoclavada, entretanto, não apresentou efeito protetor significativo nas plântulas. Portanto, a autoclavagem dos extratos brutos aquosos de $S$. cerevisiae foi necessária para a extração de moléculas eliciadoras da resistência contra o patógeno, nos cotilédones de pepineiro. Wulff e Pascholati (1999) verificaram que o filtrado de células autoclavadas de $S$. cerevisiae causou maior acúmulo de fitoalexinas em mesocótilos de sorgo, em comparação aos filtrados de células não autoclavadas. Esses resultados indicaram que as moléculas eliciadoras são, possivelmente, termoestáveis. Bonaldo (2005) verificou que preparações de $S$. cerevisiae (fermento biológico) autoclavadas sequencialmente por 1, 2, 3 e 4 horas (no total de 10 horas) induziram, aproximadamente, o acúmulo de dez vezes mais fitoalexinas em mesocótilos do sorgo do que preparações autoclavadas por 4 horas, uma única vez. Essa autora relatou que os extratos da

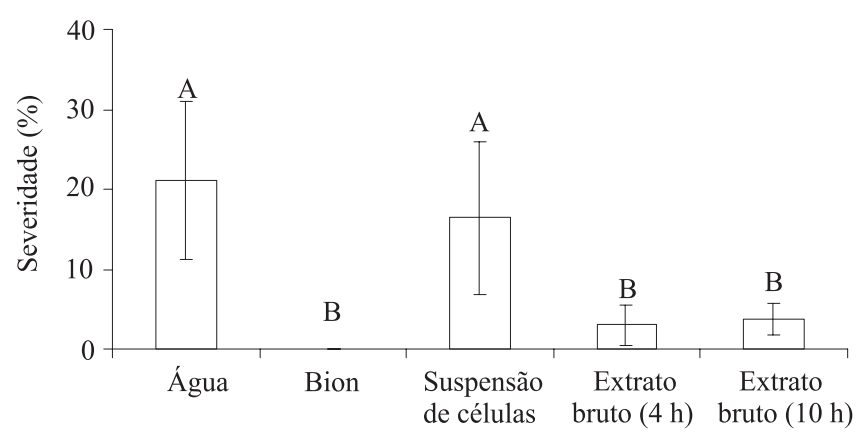

Figura 1. Efeito da pulverização com suspensão de células e extratos aquosos brutos de Saccharomyces cerevisiae autoclavados por 4 e 10 horas na proteção de plântulas de pepineiro contra antracnose. Controle negativo, água, controle positivo, Bion (produto comercial indutor de resistência). Médias \pm desvio-padrão, seguidas de letras iguais, não diferem entre si pelo teste de Tukey, a 5\% de probabilidade. $\mathrm{CV}=32,8 \%$. 
levedura autoclavados por 3 ou 4 horas, sequencialmente, apresentaram maiores concentrações de carboidratos do que os extratos autoclavados apenas uma vez.

Vários trabalhos relatam a utilização da autoclavagem para extração de componentes fúngicos com atividade eliciadora na ativação de defesas em plantas. A autoclavagem por $30 \mathrm{~min}$ a $121^{\circ} \mathrm{C}$ de esporos do fungo Mucor ramosissimus favoreceu a extração de eliciadores capazes de induzir a síntese de fitoalexinas em soja e em Rubiaceae nativas (Simões et al., 2005). O extrato bruto aquoso do micélio de Penicillium chrysogenum, denominado "Pen", eliciou respostas de defesa e induziu resistência em plantas de Arabidopsis thaliana, tomate, fumo e arroz (Thuerig et al., 2006). Para a preparação do extrato bruto, esses autores utilizaram $150 \mathrm{~g}$ de massa de matéria seca do micélio de $P$. chrysogenum foram adicionados a $1 \mathrm{~L}$ de água destilada e autoclavados por 3 horas a $140^{\circ} \mathrm{C}$.

O extrato bruto (4 horas) e o sobrenadante e precipitado provenientes de sua precipitação etanólica foram eficientes no controle da antracnose e reduziram a severidade da doença em cerca de $98 \%$ (Figura 2).

Após a realização da CTA do sobrenadante da precipitação etanólica, quatro picos foram identificados e os componentes do sobrenadande responsáveis por esses picos foram utilizados no bioensaio (Figura 3). As frações do sobrenadante não ligadas à resina DEAE-celulose (pico I da cromatografia) ou ligadas à resina (pico II) reduziram em 81 e $72 \%$, respectivamente, a severidade da antracnose, em comparação aos cotilédones tratados com água (Tabela 1). Essas frações apresentaram maior concentração de carboidratos do que de proteínas. É possível, portanto,

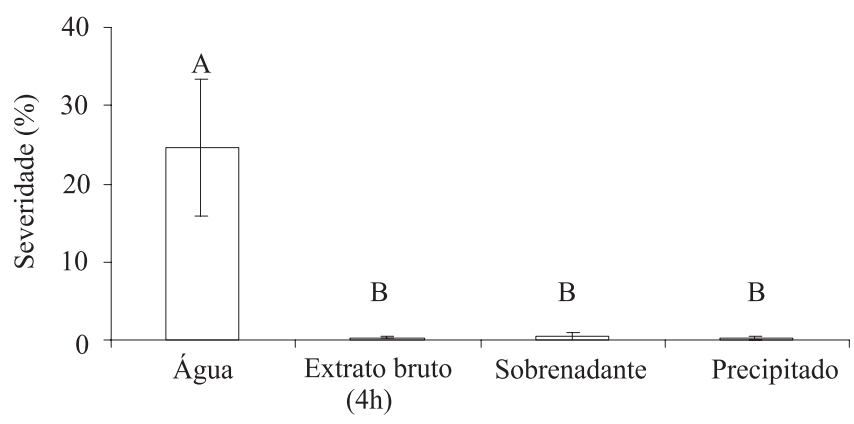

Figura 2. Efeito das preparações obtidas da precipitação etanólica do extrato bruto aquoso de Saccharomyces cerevisiae, autoclavado por 4 horas, sobre a antracnose, em cotilédones de pepineiro. Médias \pm desvio-padrão, seguidas de letras iguais, não diferem significativamente pelo teste de Tukey, a $5 \%$ de probabilidade. $\mathrm{CV}=22,22 \%$.

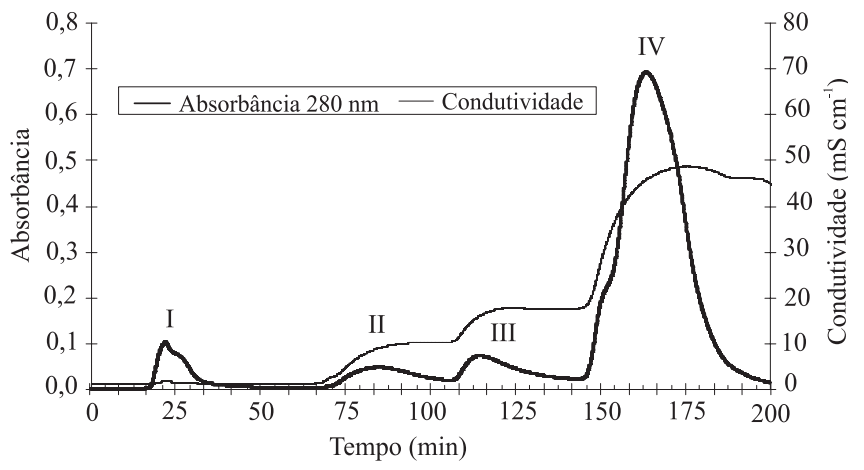

Figura 3. Cromatografia de troca aniônica do sobrenadante obtido a partir da precipitação etanólica do extrato bruto aquoso de Saccharomyces cerevisiae autoclavado por 4 horas.

Tabela 1. Conteúdo de proteínas e carboidrato totais das frações agrupadas nos picos I a IV da cromatografia de troca aniônica do extrato bruto de Saccharomyces cerevisiae autoclavado por 4 horas e seus efeitos sobre a severidade da antracnose em cotilédones de pepineiro ${ }^{(1)}$.

\begin{tabular}{lccc}
\hline Tratamento & Proteínas & $\begin{array}{c}\text { Carboidratos totais } \\
\text { Água }\end{array}$ & Severidade da antracnose \\
\hline Án & \\
Pico I & $0,011 \pm 0,007 \mathrm{E}$ & $0,553 \pm 0,037 \mathrm{~A}$ & $40,10 \pm 18,75 \mathrm{~A}$ \\
Pico II & $0,112 \pm 0,009 \mathrm{D}$ & $0,434 \pm 0,040 \mathrm{~B}$ & $7,42 \pm 3,44 \mathrm{C}$ \\
Pico III & $0,207 \pm 0,009 \mathrm{C}$ & $0,095 \pm 0,008 \mathrm{D}$ & $28,12 \pm 9,87 \mathrm{BC}$ \\
Pico IV & $0,135 \pm 0,019 \mathrm{D}$ & $0,118 \pm 0,001 \mathrm{D}$ & $33,19 \pm 13,47 \mathrm{ABC}$ \\
\hline (1) Médias \pm desvio-padrão, seguidas de letras iguais, não diferem significativamente \\
pelo teste de Tukey, a 5\% de probabilidade. (2)Percentagem de área lesionada \\
nos cotilédones pepineiro.
\end{tabular}

que os carboidratos presentes nessas frações estejam correlacionados à atividade eliciadora.

\section{Conclusões}

1. A levedura comercial Saccharomyces cerevisiae contém frações indutoras de resistência à antracnose.

2. A autoclavagem de extratos brutos aquosos de S. cerevisiae é necessária para a extração de moléculas eliciadoras da resistência a Colletorichum lagenarium, em cotilédones de pepineiro.

3. Os compostos com atividade eliciadora estão presentes no extrato bruto autoclavado, nas frações (sobrenadante e precipitado), obtidas pela precipitação etanólica de extratos brutos, e nos componentes dos picos I (frações que não se ligam à resina DEAE-celulose) e II (frações que se ligam à resina DEAE-celulose), identificados na cromatografia de troca aniônica. 


\section{Referências}

BOLLER, T. Chemoperception of microbial signals in plant cells. Plant Molecular Biology, v.46, p.189-214, 1995.

BONALDO, S.M. Efeito de Saccharomyces cerevisiae na síntese de fitoalexinas em sorgo, na germinação e formação de apressórios por fungos fitopatogênicos e na proteção de pepino a Colletotrichum lagenarium e sorgo a Colletotrichum sublineolum. 2005. 150p. Tese (Doutorado) - Escola Superior de Agricultura "Luiz de Queiroz", Piracicaba.

BRADFORD, M.A. A rapid and sensitive method for the quantitation of microgram quantities of protein utilizing the principle of protein-dye binding. Analytical Biochemistry, v.72, p.248-254, 1976.

DI PIERO, R.M.; GARCIA JUNIOR, D.; TONUCCI, N.M. Indutores bióticos. In: CALVALCANTI, L.S.; DI PIERO, R.M.; CIA, P.; PASCHOLATI, S.F.; RESENDE, M.L.V.; ROMEIRO, R. da $S$. (Ed.). Indução de resistência em plantas a patógenos e insetos. Piracicaba: FEALQ, 2005. p.29-50.

DUBOIS, M.; GILLES, K.A.; HAMILTON, J.K.; REBERS, P.A.; SMITH, F. Colorimetric method for determination of sugars and related substances. Analytical Chemistry, v.28, p.350-356, 1956.

KUROZAWA, C.; PAVAN, M.A. Doenças das cucurbitáceas. In: KIMATI, H.; AMORIN, L.; BERGAMIN FILHO, A.; CAMARGO, L.E.A.; REZENDE, J.A.M. Manual de fitopatologia. São Paulo: Agronômica Ceres, 1997. p.325-337.

KUROZAWA, C.; PAVAN, M.A.; REZENDE, J.A.M. Doenças das cucurbitáceas. In: KIMATI, H.; AMORIM, L.; REZENDE, J.A.M.; BERGAMIN FILHO, A.; CAMARGO, L.E.A. (Ed.). Manual de fitopatologia: doenças das plantas cultivadas. 4.ed. São Paulo: Agronômica Ceres, 2005. p.293-302.
LABANCA, E.R.G. Purificação parcial de elicitores presentes em Saccharomyces cerevisiae: atividade como indutores de resistência em pepineiro (Cucumis sativus) contra Colletotrichum lagenarium e da síntese de gliceolinas em soja (Glycine max). 2002. 118 p. Dissertação (Mestrado) - Escola Superior de Agricultura "Luiz de Queiroz", Piracicaba.

PASCHOLATI, S.F. Potencial de Saccharomyces cerevisiae e outros agentes bióticos na proteção de plantas contra patógenos. 1998. 123p. Tese (Livre-Docência) - Escola Superior de Agricultura "Luiz de Queiroz", Piracicaba.

SIMÕES, K.; DIETRICH, S.M.C.; HAHN, M.G.; BRAGA, M.R. Purification and characterization of a phytoalexin elicitor from spores of the saprobe Mucor ramosissimus. Revista Brasileira de Botânica, v.28, p.735-744, 2005.

STADNIK, M. Indução de resistência a oídios. Summa Phytopathologica, v.26, p.175-177, 2000.

THUERIG, B.; FÉLIX, G.; BINDER, A.; BOLLER, T.; TAMM, L. An extract of Penicillium chrysogenum elicits early defense-related responses and induces resistence in Arabidopsis thaliana independently of known signalling pathways. Physiological and Molecular Plant Pathology, v.67, p.180-193, 2005.

VALE, F.X.R.; FERNANDES FILHO, E.I.; LIBERATO, J.R. A software plant disease severity assessment. In: INTERNATIONAL CONGRESS OF PLANT PATHOLOGY, 8., 2003, Christchurch. Proceedings. Christchurch: [International Society for Plant Pathology], 2003. p.105.

WALTERS, D.; WALSH, D.; NEWTON, A.; LYON, G. Induced resistance for plant disease control: maximizing the efficacy of resistance elicitors. Phytopathology, v.95, p.1368-1373, 2005.

WULFF, N.A.; PASCHOLATI, S.F. Partial characterization of sorghum phytoalexin elicitors isolated from Saccharomyces cerevisiae. Fitopatologia Brasileira, v.24, p.428-435, 1999.

Recebido em 20 de julho de 2009 e aprovado em 29 de outubro de 2009 